\title{
Mulheres migrantes e trabalho doméstico no Brasil e no mundo
}

\author{
Migrant women and domestic work in brazil and in the world
}

Gustavo Marcel Filgueiras Lacerda

Pontifícia Universidade Católica de Minas Gerais/MG

Camila de Paula Guimarães Baía

Pontifícia Universidade Católica de Minas Gerais/MG

RESUmo A migração é um antigo fenômeno na história da humanidade. Hodiernamente, não se pode prescindir, na análise de tal fenômeno, de sua leitura a partir do recorte de gênero. Perceber o papel protagonista da mulher no seu processo de migração é fundamental para pensar o seu deslocamento, opcional ou forçado, em busca de manutenção da própria sobrevivência e/ou a dos seus dependentes. Nesse sentido, o gênero e a qualificação da mulher migrante serão decisivos para a determinação do posto de trabalho a ser ocupado no local do destino e as atividades a serem desenvolvidas. Tal definição é oriunda de uma divisão internacional sexual do trabalho, fundada no patriarcalismo. Às mulheres com pouca ou nenhuma formação, geralmente, são destinados os trabalhos do cuidado, em especial, o serviço doméstico. Assim, o presente artigo, a partir da análise do fenômeno migratório feminino, do trabalho doméstico no Brasil e no mundo e dos efeitos do trabalho doméstico a respeito da subjetividade da empregada doméstica, discorre sobre o trabalho doméstico exercido pela mulher migrante no Brasil e no mundo, evidenciando a desigualdade de gênero e fomentando a necessidade de realização de medidas que incrementem a igualdade no mundo do trabalho, tanto na perspectiva interna do país, quanto no aspecto internacional; tendo em vista o mundo globalizado e o fenômeno migratório contemporâneo.

Palavras-chave: Migração feminina. Trabalho doméstico. Divisão Internacional Sexual do Trabalho.

ABSTRACr Migration is an ancient phenomenon in the history of mankind. Today, in the analysis of such phenomenon, one cannot do without reading from the gender cut. Perceiving the protagonist role of women in their migration process is fundamental to think of their displacement, optional or forced, in order to maintain their own survival and/or that of their dependents. In this sense, the gender and qualification of migrant women will be decisive for determining the job position to be occupied at the place of destination and the activities 
to be carried out. This definition comes from an international division of labor based on patriarchalism. Women with little or no training are usually assigned to care work, especially domestic work. Thus, the present article, based on the analysis of the female migration phenomenon, domestic work in Brazil and the world, and the effects of domestic work on the subjectivity of the domestic maid, discusses the domestic work done by migrant women in Brazil and in the world, high lighting gender in equality and promoting the need for measures to promote equality in the world of work, both within the country's internal perspective and on the international front; taking into account the globalized world and the contemporary migratory phenomenon.

Keywords: Female migration. Domestic work. International Division Sexuality OF THE WORK.

\section{INTRODUÇÃo}

A análise do fenômeno migratório laboral a partir do recorte de gênero, cada vez mais, tem ocupado um importante papel na análise da migração interna e externa. A migração feminina não pode ser concebida apenas em um papel secundário, em que a mulher migra apenas para acompanhar seu pai, marido, entre outros do gênero masculino. É a mulher, também, protagonista de seu processo migratório, motivado por fatores diversos, entre os quais se destaca o trabalho, o desemprego, busca de melhores oportunidades de sustento próprio e/ou familiar etc. Assim, o gênero e a qualificação da mulher migrante são fundamentais para determinar os postos de trabalho que ocuparão, sendo estes, ainda hoje, balizados por uma divisão internacional sexual do trabalho.

Nesse cenário, o foco deste artigo está nas mulheres migrantes que ocupam os postos de trabalho doméstico no Brasil. Para tanto, em um primeiro momento, discorrer-se-á por uma breve análise do fenômeno migratório, seu conceito e sua interseccionalidade com o gênero feminino, demonstrando o acesso da mulher migrante ao trabalho doméstico. Em seguida, a fim de compreender a evolução histórica desempenhada pela mulher no trabalho doméstico, passar-se-á à análise dessa forma de trabalho, bem como. de sua regulamentação e de como o trabalho doméstico se encontra no Brasil e no mundo. A partir disso, analisar-se-ão os efeitos que tal trabalho ocasiona na subjetividade da trabalhadora doméstica para, por fim, demonstrar a situação da mulher migrante doméstica no Brasil e no mundo.

\section{MigraÇão FEMININA E A diVisão INTERNACIONAL SEXUAL do TRABALHO}

A palavra migração vem do latim migratio, que significa deslocamento de uma ou mais pessoas de um lugar para outro, com caráter provisório ou definitivo, geralmente motivada por questões políticas ou econômicas (MICHAELIS, 2016). Para a Organização Mundial das Nações Unidas, a migração é:

[...] o fato de que envolve uma mudança do local de residência, ou do lugar de residência 'habitual', ou seja, ir viver em um lugar novo ou diferente [...] Portanto, a migração é operacionalmente definida como uma mudança de residência de uma divisão civil a outra” (ORGANIZAÇÃO DAS NAÇÕES UNIDAS, 1972). 
Essa migração poderá ser interna, na hipótese de acontecer dentro de um mesmo território nacional ou externa, se o deslocamento ocorrer de um país para outro. Ambas englobam algumas espécies. No âmbito interno, a migração poderá acontecer de forma a caracterizar o êxodo rural (deslocamento do âmbito rural para a cidade), Urbano-rural (onde ocorre o deslocamento da cidade para o campo), Urbano-urbana (deslocamento de uma cidade para outra) ou Sazonal (migração interna de pessoas em determinadas épocas do ano). A migração Urbano-urbana ainda compreende uma subespécie, trata-se da migração pendular, ou seja, quando uma pessoa migra de uma cidade para trabalhar em outra, mas volta para a anterior ao final do dia (ALMEIDA, 2018). Já as migrações externas podem acontecer de forma regular (quando o imigrante ingressa no país destino de forma a atender a legislação local para tanto) e irregular (quando o imigrante viola a legislação de ingresso do país destino ou quando qualquer pessoa permanece no mesmo sem que haja autorização) (ORGANIZAÇÃO INTERNACIONAL PARA AS MIGRAÇÕES, 2014).

No que se refere à motivação, conforme a Organização Internacional para as Migrações (2014), as migrações podem ser voluntárias ou forçadas. Na primeira hipótese, as pessoas se deslocam em busca de uma melhor qualidade de vida, ou seja, visam no destino um melhor acesso a trabalho, saúde, educação, entre outros. Já a migração forçada caracteriza-se pela obrigação de deslocamento oriunda de fatores externos à decisão pessoal, sem os quais a(s) pessoa(s) permaneceria(m) no local de origem. É o que acontece, por exemplo, com os exilados e refugiados, migração fruto de desastres naturais, escravidão, entre outros.

Entre as características já elencadas, destaca-se, para este estudo, as migrações voluntárias cuja finalidade é o melhor acesso ao trabalho. Conforme Dutra:

\begin{abstract}
De acordo com a Organização Internacional para as Migrações (OIM), a migração laboral no século XXI se destaca como um dos assuntos principais na agenda política de muitos países, sejam esses, países de origem, trânsito ou de destino de migrantes. Três fatores se identificam como essenciais para explicar esse fenômeno: primeiro, as mudanças demográficas e as necessidades do mercado de trabalho em muitos países industrializados; segundo, a pressão da população, o desemprego e as crises internacionais que atualmente afetam tanto países industrializados quanto os menos desenvolvidos; terceiro, a formação de redes entre países baseadas na família, na cultura e na história" (DUTRA, 2013, p. 179/180).
\end{abstract}

Assim, para Francisco (2018), a migração interna no Brasil, historicamente, possui uma forte característica de êxodo rural, tendo em vista o movimento que o modelo econômico capitalista gera no campo, pois com a automatização das atividades agrícolas e o favorecimento desse modelo aos latifundiários, as trabalhadoras e os trabalhadores do campo se veem obrigados a ir para as cidades em busca de trabalho. Nesse sentido, até o final do século XX, a região sudeste foi a que mais recebeu esse fluxo migratório de trabalhadores. Porém, a partir da década de 1970, o fluxo migratório para o Sudeste sofreu certa retração no fluxo migratório, tendo em vista a estagnação econômica que atingiu o país nesse período e a queda da procura de mão de obra. Assim, o Norte do país e o Centro-oeste, graças às políticas públicas de fomento à industrialização dessas regiões, passou a exercer maior atração sobre migrantes do que em períodos anteriores. 
Nesse bojo, merece a atenção a migração laboral feminina. Compreender o fenômeno migratório pelo viés do gênero feminino é dar relevância a um processo que, há tempos, subordinava-se ao masculino, ou seja, a migração feminina era entendida em um papel secundário, tendo a mulher migrante como aquela que acompanha o pai, o marido, entre outros, mas, jamais como protagonista (SERTÓRIO e SANTOS, 2018, p. 2). Dessa forma, tratar a migração sob o enfoque do gênero supõe compreender:

(...) por um lado, a significação da construção social da feminilidade, da masculinidade e a desigualdade que se produzem entre os sexos e, por outro, o papel que jogam tais construções na decisão das mulheres de migrar assim como o status que a sociedade de acolhida lhes outorga (ROCA I GIRONA in DUTRA, 2012, p. 68).

Assim, é preciso compreender que o fenômeno migratório está relacionado às estratégias familiares para a própria manutenção, oriunda da estruturação das suas relações e de gênero (SERTÓRIO e SANTOS, 2018, p. 2). Dessa forma, nem sempre a escolha por migrar, conforme já dito, ocorre por uma deliberação racional e livre, mas pode ser fruto da necessidade verificada no contexto social no qual a pessoa que migrará está inserida. Portanto, as motivações para a migração feminina podem ser diversas, sendo as mais comuns, conforme Dutra (2013, p. 180): trabalho, desemprego, condições de precariedade, falta de reconhecimento, necessidade de capacitação, discriminação retributiva, segregação ocupacional, vulnerabilidade, entre outras. Além disso, percebe-se também como fatores que influenciam a migração feminina: a expansão da rede de contatos das migrantes, a necessidade de aumentar e diversificar a renda da família, uma cultura de migração, a pobreza e a falta de oportunidades, a violência e opressão para com a mulher dentro do próprio núcleo familiar e comunitário, assim como a vontade de se emancipar e realizar sonhos.

Todos esses fatores fazem com que algumas mulheres deixem suas comunidades de origem, suas famílias e vínculos afetivos para descobrir e participar de novas formas de vida que lhes permitam abrir outras portas, tanto para elas quanto para suas famílias, independente que isso acabe acontecendo ou não. Dessa forma, elas desenham novas rotas de vida, buscando dar respostas às necessidades do dia a dia. Necessidades que dizem respeito não só à escassez material, que impede uma alimentação saudável, vestimenta e moradia digna, como também à falta de acesso à educação formal para os filhos e para elas próprias, à falta de acesso ao mercado de trabalho formal, ou inclusive informal, e à falta de acesso aos serviços públicos, tais como, saúde e transporte.

A necessidade de dar sustento à família é uma forte motivação para a migração em geral e para a migração feminina em particular. As mulheres migrantes são os principais agentes ativos no envio de remessas aos seus países de origem, acompanhando a crescente tendência de aumento do número das famílias monoparentais, o que se denomina de feminização da pobreza (DUTRA, 2013, p. 180).

Nesse processo migratório em busca de garantir sustento familiar, o que não é uma especificidade da migração masculina, o gênero é determinante na busca do emprego e no recrutamento das mulheres migrantes. Este define as tarefas que desempenharão e outras que não farão. 
A divisão sexual do trabalho é um fenômeno que pode ser observado de forma muito clara na alta concentração das mulheres nas tarefas consideradas de reprodução no âmbito doméstico e em determinados postos de trabalho. Trata-se de um conceito que faz referência a formas de inserção diferenciada de homens e mulheres na divisão do trabalho existente, tanto nos espaços de reprodução quanto nos de produção social. ${ }^{30} \mathrm{E}$ isso acontece porque é "a construção social da diferença como desigualdade que age como fator estruturante na divisão do trabalho. (COMAS D'ARGEMIR, 2009, p.170 in DUTRA, 2013, p. 189).

Além do gênero, também será determinante a qualificação da migrante. Se esta possui boa formação, ocupará postos de trabalho melhores que outras que não têm formação ou a possuem de modo insuficiente. Dessa forma, àquelas que têm pouca ou quase nenhuma formação, geralmente, tanto em âmbito de migração interna, quanto de migração externa, lhes é destinado o trabalho do cuidado, preferencialmente, o trabalho doméstico. Isso porque:

A mulher imigrante é percebida como força de trabalho idônea para realizar o trabalho doméstico remunerado, sendo que se trata de uma atividade socialmente pouco valorada, etiquetada como "suja" e escassamente qualificada, assumida como algo inerente à condição feminina e amiúde realizada desde a economia informal (PARELLA RUBIO, 2005, p. 98-99).

Nesse cenário, percebe-se o trespasse das funções domésticas entre mulheres, ou seja, da mulher autóctone para a mulher migrante, reforçando a divisão sexual do trabalho e o papel da mulher como responsável pelo âmbito doméstico.

Assim, antes de entrar na análise da mulher migrante no trabalho doméstico no Brasil e no mundo, necessário se faz observar como essa espécie de trabalho surge na História e como se torna, por uma divisão sexual do trabalho oriunda de uma sociedade patriarcal, lugar da mulher.

\section{Trabalho DOMÉSTICO}

\section{Origem do trabalho doméstico}

O trabalho doméstico tem sua origem na pré-história, época em que cabia ao gênero feminino o cuidado com a cria, o preparo das refeições e ao homem o trabalho de caça e procura de abrigo. Percebe-se que a essência da divisão sexual do trabalho não sofreu maiores alterações até os dias de hoje, eis que cabe à mulher o trabalho interno no âmbito doméstico e ao homem o trabalho externo (COTRIN, 2002).

$\mathrm{Na}$ civilização grega antiga cabia à mulher, que não possuía direitos políticos, ou aos escravos a realização do trabalho doméstico. Ressalte-se que o trabalho executado pelo escravo era considerado inferior, indigno de um cidadão (COTRIN, 2002).

No Brasil, o trabalho doméstico teve sua origem no trabalho escravo. Na época colonial, a atividade doméstica era exercida, em sua maioria, por mulheres, negras, que trabalhavam como mucamas, amas de leite, cozinheiras, arrumadeiras e costureiras. As trabalha- 
doras domésticas moravam na senzala, mas passavam o dia na casa grande. Com o passar do tempo e o redimensionamento das casas urbanas, esses dois lugares fundiram-se e foi criado um novo cômodo: quarto de empregada, sendo esse um dos resquícios da escravidão. Conforme Maria Helena Pereira Toledo Machado (2018):

\begin{abstract}
[...] o trabalho doméstico foi quase monopolizado por mulheres. Outros trabalhos, inclusive o de plantação, podiam ser realizados por mulheres e homens. Enquanto durou o tráfico, no mundo colonial inglês e francês as mulheres foram preferidas para o trabalho na agricultura, formando sociedades com maioria de escravizadas. No mundo ibérico, o preferido para o trabalho agrícola era o homem, compondo sociedades com minoria de mulheres escravizadas. Mais tarde, a reprodução natural tendeu a equilibrar os sexos (MACHADO, 2018, p. 335).
\end{abstract}

No Brasil Império, mesmo após a libertação dos escravos, com a Lei Áurea (13 de maio de 1888), muitos continuaram servindo seus patrões em troca de moradia e alimentação, por falta de oportunidades. Não tinham o que fazer nem para onde ir (SOUZA, 2013, p. 138).

No Brasil República, desde 1889 até os dias atuais, o empregado doméstico começou a sair da invisibilidade e gradativamente passou a conquistar mais direitos; porém, ainda, com várias limitações à equiparação com os empregados urbanos e rurais, como se verá a seguir.

\title{
Evolução legislativa do trabalho doméstico no Brasil
}

A primeira norma que trata do trabalho doméstico no Brasil é o Código de Posturas sobre Criados e Amas de Leite do Município de São de Paulo, de 1886 (SÃO PAULO, 1886).

O Código Civil de 1916, nos artigos 1.216 a 1.236, disciplinou os contratos de locação de serviços dos empregados em geral, sendo utilizado inclusive para o trabalhador doméstico, a despeito de não estar explícita a locação de serviços domésticos. Os artigos já mencionados tratavam da retribuição dos serviços prestados, do prazo, do pré-aviso, além da dispensa por justa causa dos serviços locados (BRASIL, 1916).

O Decreto 16.107/1923 definiu o trabalhador doméstico como cozinheiros, ajudantes de cozinha, copeiros, arrumadores, lavadeiras, engomadeiras, jardineiros, hortelões, porteiros, serventes, enceradores, amas de leite, amas-secas, costureiras, damas de companhia. Foram equiparados a trabalhador doméstico todos aqueles que trabalhassem em hotéis, restaurantes, casas de pasto, pensões, bares, escritórios, desde que exercessem atividades de natureza doméstica (BRASIL, 1923).

Em 1932, após forte movimentação das trabalhadoras domésticas surgiu a Associação dos Empregados Domésticos de Santos, criada por Laudelina de Campos Melo, primeira do gênero no Brasil.

O Decreto-Lei 3.078 de 1941 conceituou os trabalhadores domésticos como aquelas pessoas que, mediante remuneração, prestassem serviços em residências particulares ou em benefício dessas. Dessa forma, desconstituiu a possibilidade dos trabalhadores de hotéis, restaurantes, pensões, bares e escritórios, serem enquadrados como empregados domésti$\cos$ (BRASIL, 1941). 
O Decreto-Lei $n^{\circ} .5 .452$, de $1^{\circ}$. de maio de 1943 - Consolidação das Leis do Trabalho - não regulou o trabalho doméstico (BRASIL, 1943).

Com o advento da Lei 5.859 de 1972 os empregados domésticos passaram a ter acesso a alguns direitos: benefícios e serviços da Previdência Social, férias anuais $+1 / 3$ e carteira de trabalho (BRASIL, 1972).

O Decreto 95.247/1987contemplou as domésticas com o vale transporte (BRASIL, 1987).

A Constituição da República Federativa do Brasil de 1988 (CF/88) concedeu aos trabalhadores domésticos alguns direitos, previstos em nove dos 34 incisos do artigo $7^{\circ}$., a saber: salário mínimo, irredutibilidade de salário, $13^{\circ}$. salário com base na remuneração integral, repouso semanal remunerado, férias anuais remuneradas com um terço a mais, licença maternidade, licença paternidade, aviso prévio, aposentadoria por idade, tempo de contribuição e invalidez (BRASIL, 1988).

A Lei 10.208 de 2001 facultou o recolhimento do FGTS e o seguro-desemprego. Como a medida estava sujeita à liberalidade do empregador, a previsão legal teve eficácia bastante reduzida (BRASIL, 2001).

O primeiro real e grande avanço veio com a Lei 11.324, de 19 de julho de 2006, que agregou aos direitos dos trabalhadores domésticos o direito a descanso semanal remunerado aos domingos e feriados, ao pagamento em dobro do trabalho em feriados civis e religiosos, 30 dias corridos de férias, garantia de emprego à gestante, vedou descontos por fornecimento de alimentação, higiene, vestuário e moradia (BRASIL, 2006).

\section{Emenda Constitucional $n^{\circ} .72$ de 2013}

A Emenda Constitucional (EC) no. 72, popularmente chamada de "PEC das Domésticas", alterou a redação do parágrafo único do artigo $7^{\circ}$. da $\mathrm{CF} / 88$, para estabelecer a igualdade de direitos trabalhistas entre os trabalhadores domésticos e os demais trabalhadores urbanos e rurais. O referido dispositivo legal traz a seguinte redação:

\footnotetext{
São assegurados à categoria dos trabalhadores domésticos os direitos previstos nos incisos IV, VI, VII, VIII, X, XIII, XV, XVI, XVII, XVIII, XIX, XXI, XXII, XXIV, XXVI, XXX, XXXI e XXXIII e, atendidas as condições estabelecidas em lei e observada a simplificação do cumprimento das obrigações tributárias, principais e acessórias, decorrentes da relação de trabalho e suas peculiaridades, os previstos nos incisos I, II, III, IX, XII, XXV e XXVIII, bem como a sua integração à previdência social (BRASIL, 2013).
}

Os incisos já mencionados referem-se a salário mínimo, irredutibilidade salarial, garantia do mínimo no caso de remuneração variável, $13^{\circ}$. salário, proteção do salário, jornada de 8 horas diárias e 44 semanais, repouso semanal remunerado (RSR), remuneração do serviço extraordinário, férias $+1 / 3$, licença gestante, licença-paternidade, aviso prévio, normas de higiene e segurança, aposentadoria, reconhecimento de acordos e convenções coletivas, proibição de diferença de salários, proibição de discriminação do trabalhador portador de deficiência, proibição de trabalho noturno, perigoso e insalubre para menor de 18 anos de idade e de qualquer trabalho a menor de 16, salvo na condição de aprendiz, a partir de 14 
anos de idade, indenização compensatória no caso de dispensa sem justa causa, seguro-desemprego, Fundo de Garantia por Tempo de Serviço (FGTS), adicional noturno, salário-família, assistência gratuita em creche e pré-escola, seguro contra acidentes de trabalho.

Ocorre que não foram estendidos aos domésticos os direitos previstos nos incisos $\mathrm{V}$ (piso salarial), XIV (jornada de seis horas para o trabalho realizado em turnos interruptos de revezamento), XX (proteção do mercado de trabalho da mulher, mediante incentivos específicos), XXIII (adicional de penosidade, insalubridade e periculosidade), além dos inaplicáveis à categoria, quais sejam, incisos XI, XXVII, XXXII e XXXIV. Assim, em que pese o avanço, ainda não há a completa equiparação do empregado doméstico aos demais empregados pela legislação pátria.

\section{Lei complementar 150/2015}

Em $1^{\circ}$. de junho de 2015, foi aprovada a Lei Complementar (LC) n ${ }^{\circ}$. 150, que regulamentou a EC 72, concedendo ao trabalhador doméstico, teoricamente, os mesmos direitos de um trabalhador celetista (BRASIL, 2015).

Não foram estendidos aos domésticos os direitos previstos nos incisos $\mathrm{V}$ (piso salarial), XIV (jornada de seis horas para o trabalho realizado em turnos interruptos de revezamento), XX (proteção do mercado de trabalho da mulher, mediante incentivos específicos), XXIII (adicional de penosidade, insalubridade e periculosidade), além dos inaplicáveis à categoria, quais sejam, incisos XI, XXVII, XXXII e XXXIV.

A LC 150, em seu artigo $1^{\circ}$., traz novo conceito de empregado doméstico:

Artigo $1^{\circ}$. - Ao empregado doméstico, assim considerado aquele que presta serviços de forma contínua, subordinada, onerosa e pessoal e de finalidade não lucrativa à pessoa ou à família, no âmbito residencial destas, por mais de 2 (dois) dias por semana, aplica-se o disposto nesta Lei (BRASIL, 2015).

Com essa definição legal, pode-se entender que ficam excluídas do conceito de empregado doméstico as diaristas, ou seja, trabalhadoras que prestam seus serviços de forma contínua, subordinada, onerosa, pessoal, de finalidade não lucrativa, à pessoa ou família, no âmbito residencial dessas, por até dois dias na semana.

No que tange à continuidade do trabalho, antes da entrada em vigor da LC $150 / 2015$, havia calorosas discussões a respeito da diferença entre a configuração do emprego doméstico para o trabalho dos diaristas, em que não há vínculo empregatício. Os serviços prestados por diaristas que comparecem ao trabalho, uma ou duas vezes na semana, não se confundem com o trabalho doméstico previsto na LC 150/2015, eis que ausentes os requisitos da continuidade na prestação de serviços e da subordinação. Da dicção desse preceito legal é inescapável a conclusão de que a continuidade constitui um dos principais elementos configuradores do empregado doméstico, o que não se confunde com a não eventualidade exigida como elemento caracterizador da relação de emprego nos moldes da CLT. Logo, não é doméstica a faxineira de residência que presta seus serviços em períodos descontínuos, ante a ausência na relação jurídica do elemento da continuidade (CASTRO et al., 2015). 
Pergunta-se se é aceitável que esse elemento temporal, apenas ele, possa delimitar quem será ou não considerado como empregado doméstico.

Não resta dúvida de que quem se programa para trabalhar como diarista duas vezes por semana, em casa de família, organiza sua rotina, seus afazeres, da mesma forma daquela que, como empregada doméstica, se programa para trabalhar, realizando as mesmas atividades, três vezes por semana. No entanto, é perceptível que, com essa situação, está se perpetuando uma legião de pessoas trabalhando sem direitos trabalhistas e sem acesso à seguridade social.

Percebe-se, assim, que ainda que as diaristas possam prestar serviços como microempreendedor individual, formalmente, com direito à seguridade social, elas devem arcar com carga tributária e não terão os direitos trabalhistas previstos para as trabalhadoras categorizadas como domésticas. Contudo, as diaristas, em sua grande maioria, atuam na informalidade, não pagando tributos, sem comprovação de renda, não tendo acesso aos benefícios previdenciários e outras vantagens disponíveis apenas para os trabalhadores formais.

\section{Convenção $n^{\circ} .189$ da Organização Internacional do Trabalho (OIT)}

De acordo com Alice Monteiro de Barros (2012), os tratados e as convenções internacionais incluem-se entre as fontes formais do Direito do Trabalho, desde que ratificados pelos países, o que é o caso do Brasil. Por tratados, segundo a autora, entende-se, em sentido amplo, todo acordo de vontade entre dois ou mais sujeitos de direito internacional, escrito, com vista a produzir efeitos jurídicos e cuja abrangência é dada pela Convenção de Viena. Assevera a jurista acerca dos tratados e convenções internacionais:

\footnotetext{
Alguns autores, de cujo ponto de vista compartilhamos, incluem entre as fontes do Direito do Trabalho os tratados e as convenções internacionais, desde que ratificados pelos países. São fontes formais, mas dependem de ratificação. Uma vez ratificadas, passam a integrar o rol de leis internas do respectivo país, perdendo relevância a distinção entre fontes internas e de origem internacional (BARROS, 2012, p. 91).
}

A Convenção nº 189 da OIT - Convenção sobre o Trabalho Decente para as Trabalhadoras e os Trabalhadores Domésticos - entrou em vigor em 5 de setembro de 2013. Já no Brasil, a supracitada convenção 189 foi internalizada por meio do decreto legislativo 172/17, aprovado em 5 de dezembro de 2017 (BRASIL, 2017). Em 31 de janeiro de 2018, o Brasil ratificou a Convenção $n^{\circ} .189$ da OIT (ORGANIZAÇÃO INTERNACIONAL DO TRABALHO, 2018).

Até o momento, de acordo com a OIT (2019), 27 países ratificaram a Convenção $\mathrm{n}^{\mathrm{o}}$. 189, a saber: Argentina, Bélgica, Bolívia, Brasil, Chile, Colômbia, Costa Rica, República Dominicana, Equador, Finlândia, Alemanha, Granada, Guiné, Guiana, Irlanda, Itália, Jamaica, Ilhas Maurício, Nicarágua, Panamá, Paraguai, Peru, Filipinas, Portugal, África do Sul, Suíça, Uruguai.

A Convenção $n^{\circ} .189$ trata, principalmente, de medidas efetivas para garantir direitos humanos e fundamentais do trabalho doméstico, da idade mínima para o trabalho domés- 
tico, da adoção de medidas para proteção contra abusos, do assédio e violência, das condições de emprego equitativas e trabalho decente, da proteção aos trabalhadores domésticos migrantes, das remunerações e proteção social, da inspeção do trabalho e do acesso a instâncias de resoluções de conflitos.

Situação atual do trabalho doméstico no Brasil

Segundo a OIT (2016), o Brasil tinha 6,158 milhões de trabalhadores domésticos, dos quais $92 \%$ eram mulheres. Apenas $42 \%$ desses trabalhadores contribuem para a previdência social e só $32 \%$ possuem carteira de trabalho assinada.

A grande maioria dos trabalhadores domésticos é mensalista. As diaristas, por sua vez, enfrentam a possibilidade de situações de trabalho mais precárias e têm sua própria responsabilidade de contribuir para a previdência social. Nesse cenário, apenas $4 \%$ das trabalhadoras domésticas e dos trabalhadores domésticos são sindicalizados.

O número de crianças e adolescentes em situação de trabalho infantil doméstico no Brasil teve uma diminuição de 61,6\% entre 2004 e 2015, passando de 406 mil para 156 mil.

Segundo o Instituto Brasileiro de Geografia e Estatística (2017), por meio da PNAD Contínua relativa ao trimestre encerrado em outubro de 2017 , houve um aumento de $2,9 \%$ no número de trabalhadores domésticos, ou cerca de 177 mil postos de trabalho frente ao trimestre terminado em julho, o que demonstra uma tendência de crescimento desse mercado.

Porém, segundo a pesquisa, a geração de postos de trabalho aconteceu, principalmente, com a contratação de trabalho doméstico sem carteira, por falta de espaço na economia formal.

A implementação da Lei Complementar 150, em 2015, coincidiu com o início da recessão no Brasil, impedindo a formalização de muitas trabalhadoras.

Percebe-se que, mesmo após mais de dois anos de vigência da Lei Complementar 150, em 2015, que amplia os direitos dos trabalhadores domésticos, a informalidade ainda permanece em larga escala.

\section{Situação atual do trabalho doméstico no mundo}

Os trabalhadores domésticos representam uma parte significativa da força de trabalho global no emprego informal e estão entre os grupos de trabalhadores mais vulneráveis. Eles trabalham para casas de família, muitas vezes sem termos claros de emprego, sem registro formal e excluídos do âmbito da legislação trabalhista. $O$ trabalho doméstico representa o núcleo duro do déficit de Trabalho Decente no Brasil e no mundo.

De acordo com a OIT (2016), existem 67 milhões de trabalhadores domésticos adultos no mundo, segundo estimativas da OIT para 2013. Desse número, 80\% ou 55 milhões são mulheres. A América Latina e o Caribe contam com 18 milhões de trabalhadores domésti$\cos$, dos quais $88 \%$ são mulheres.

Nesse bojo, cerca de $90 \%$ dos trabalhadores domésticos no mundo não têm acesso à seguridade social. Além disso, o trabalho doméstico é uma das ocupações com níveis de remuneração mais baixos no mundo, com médias de salário abaixo da metade do salário médio no mercado de trabalho. 
De acordo com a Organização das Nações Unidas (2017), o trabalho doméstico não remunerado representa de $10 \%$ a 39\% do Produto Interno Bruto (PIB) dos países, comprovando que o trabalho não remunerado das mulheres de cozinhar, limpar a casa, cuidar de crianças e idosos dá uma enorme contribuição econômica que permite suprir necessidades em matéria de serviços públicos e infraestrutura.

A ONU Mulheres (2017), agência da Organização das Nações Unidas, questiona o motivo pelo qual esse trabalho não é dividido nem contabilizado, pois são uma carga e barreira injusta para a igualdade de participação das mulheres no mercado de trabalho e na igualdade de remuneração.

Segundo a organização, é necessário adotar políticas que permitam reduzir e redistribuir o trabalho doméstico não remunerado, por exemplo, por meio do aumento de empregos remunerados no mercado do cuidado e investir em sistemas que proporcionem água, eletricidade, transporte e outras necessidades básicas para reduzir o trabalho doméstico.

Além disso, sugerem proposta que incentivem os homens a dividir o trabalho de cuidado e o trabalho doméstico.

\section{Impacto do trabalho na subjetividade das empregadas domésticas}

O psiquiatra francês Louis Le Guillant (2006) foi pioneiro no estudo das consequências do trabalho doméstico na saúde mental. Ele constatou o aumento de empregadas domésticas entre os pacientes psiquiátricos do hospital em que trabalhava, na França. Para ele, a experiência como empregada doméstica, mesmo para aquelas que deixaram essa profissão, deixou ou deixará marcas na sua formação/história, enquanto sujeito.

Para Louis Le Guillant (2006), a "condição" de doméstica se torna objeto do ressentimento que, associado ao sentimento de humilhação, está bastante presente na fala de suas pacientes. A humilhação se faz visível nos elementos que designam a "condição" de doméstica: o modo de se vestir, o quarto de dormir, até mesmo a linguagem, além das relações de dependência e submissão.

As empregadas domésticas são também marcadas por sentimentos ambíguos (admiração, inveja, ciúmes, ódio, amor) em relação aos patrões, à afeição que sentem pelas crianças da família, a um relacionamento de proximidade, mas marcado pela dependência e pelo isolamento que impedem qualquer tentativa de oposição organizada, como categoria.

As relações ambivalentes entre as empregadas e suas patroas são objeto de produções literárias e cinematográficas, que revelam a submissão, mas também a resistência e o enfrentamento, por vezes violento, vividos pela empregada doméstica.

O caso das "irmãs Papin", duas irmãs e empregadas, que mataram de forma brutal a patroa e sua filha, em 1933, na cidade de Le Mans, França, foi objeto de dois filmes "Entre elas", de 1994 e "O caso das Irmãs Assassinas", de 2000.

\section{Domésticas migrantes no Brasil e no mundo}

O serviço doméstico remunerado tem um papel importante na absorção das mulheres de menor escolaridade e sem experiência profissional no mercado de trabalho. Assim, perce- 
be-se que o trabalho doméstico, de forma constante ou intermitente, há muito absorve a mão de obra feminina, estando estreitamente ligado ao movimento migratório, interno e externo.

Segundo Lisboa (2007, p. 810), no contexto interno, um grande contingente de pessoas, principalmente mulheres, migra com o intuito de buscar oportunidades de emprego, acesso à educação, conquista da independência econômica e social de suas famílias de origem, possibilidade de alcançar mobilidade social, melhorar de status em relação ao emprego que exerciam nos locais de origem, acesso a serviços básicos, atendimento à saúde, ir atrás da rede familiar, de conhecidos ou amigos que já se encontram no local e até mesmo para conhecer e vivenciar experiências em um local diferente.

Importante ressaltar que para as trabalhadoras domésticas migrantes o trabalho é associado a estratégias de sobrevivência, mobilidade social e autonomia.

Conforme a OIT (2017), no contexto global dos 67,1 milhões de trabalhadores domésticos no mundo, 11,5 milhões - ou 17,2\% - são migrantes internacionais. Cerca de 73,4\%, ou aproximadamente 8,5 milhões, de todos os trabalhadores migrantes do setor são mulheres.

No Sudeste da Ásia e no Pacífico estão 24\% do total de mulheres trabalhadoras domésticas migrantes, seguidas da Europa (norte, sul e na região ocidental), com 22,1\% do total, e dos Estados árabes, com 19\%.

Para Lisboa (2007, p. 154), historicamente, ocorre um fluxo predominante de certos países para outros, geralmente em razão dos processos de colonização: as norte-africanas vão trabalhar na França, Espanha ou Itália; as peruanas, dominicanas e outras latino-americanas vão para a Espanha, Itália, Portugal ou Estados Unidos; as filipinas e indonésias são as preferidas na Alemanha, Inglaterra e Canadá; as albanesas, eritreias e etíopes vão trabalhar na Grécia e na Itália; por sua vez, as polonesas e russas têm ido em número cada vez maior para a França, Itália, Alemanha e Espanha.

Costa (2012) assevera a existência de uma política migratória fortemente restritiva na União Europeia, que, em pouco tempo, faz que mulheres latino-americanas que chegam à Europa com vistos de turista ou de estudante se tornem migrantes não-documentadas.

Apesar dos esforços dos governos europeus para permitir somente a entrada de trabalhadores altamente qualificados, na sombra dessas políticas de controle, há a demanda por trabalhadores para executar o trabalho sujo, perigoso e degradante, na maioria das vezes sem qualquer contrato escrito, a despeito de nos países europeus existir legislação que garante inúmeros direitos às domésticas.

De acordo com Costa (2012):

\begin{abstract}
Antes de pensar o lar como um espaço ausente da intervenção governamental, Gutiérrez-Rodríguez demonstra como as políticas governamentais concernentes à migração conformam o encontro da trabalhadora latino-americana não-documentada com a empregadora europeia. Essa influência do Estado sobre o encontro de duas mulheres é nomeado por Gutiérrez-Rodríguez como governo a distância. Essa forma de governar a distância cria a impressão de escolhas pessoais, quando na verdade estas escolhas são feitas dentro de uma clara racionalidade e política engendrada pelas políticas nacionais (COSTA, 2012).
\end{abstract}

Assim como nos países do Norte, no Brasil a contratação pelas famílias de empregadas domésticas é o que permite às mulheres escolarizadas, normalmente brancas, se dedicarem ao desenvolvimento profissional e pessoal. 
Conforme Costa (2012), a desvalorização do trabalho doméstico mobilizou mulheres, principalmente migrantes latino-americanas não documentadas, a se mobilizarem nos níveis locais, nacionais e internacionais, em busca de direitos trabalhistas internacionais.

Integrantes dos movimentos Mujeres Sin Rostro, Precarias a la Deriva e Servicio Doméstico Activo (SEDOAC) na Espanha; Sans Papiers Movement e Kalayaan no Reino Unido; Respect, na Alemanha, e Maiz, na Áustria, promoveram diversas ações contra as condições sub-humanas, assim como sindicatos, movimentos sociais, entre outros atores sociais, o que resultou na aprovação, no dia 16 de junho de 2011, da Convenção 189 da OIT - Convenção sobre Trabalho Decente para os Trabalhadores e Trabalhadoras Domésticas.

A migração no Brasil, em especial nas grandes cidades, vem se modificando com o passar dos anos. Inicialmente, percebia-se somente a migração da zona rural, das cidades do interior para as cidades grandes. Hoje se observa, com grande frequência, a migração internacional, principalmente de pessoas vindas de países em conflito ou que sofreram catástrofes naturais, como é o caso da Síria, do Haiti e da Venezuela.

De acordo com Illes (2018):

\begin{abstract}
A realidade migratória no Brasil, em especial nas grandes cidades, vem mudando através dos anos, contemplando, no contexto internacional, a tendência à feminização das migrações, sendo cada vez mais visível o papel das mulheres na sociedade. Desse modo, é possível traçar um paralelo entre a crescente autonomia feminina nos fluxos migratórios e a necessidade de se estabelecer no país de chegada, levando-as a buscar no serviço doméstico a sua fonte de sustento e moradia, o que as deixa, muitas vezes, em situação de vulnerabilidade ou, até mesmo, de trabalho escravo (ILLES, 2018).
\end{abstract}

No Brasil, recentemente, após investigação do Ministério Público do Trabalho de São Paulo, foram identificadas 180 pessoas, entre homens e mulheres trazidos das Filipinas, Chipre, Hong Kong, Dubai, Cingapura e Nepal para realizar trabalho doméstico em residências de classe alta no Brasil, em condições análogas à escravidão.

Diante disso, o Ministério Público do Trabalho ajuizou ação civil pública em face das empresas agenciadoras e dos seus sócios.

A sentença nos autos do processo em trâmite perante o Tribunal Regional do Trabalho da $2^{\text {a }}$ Região processo ACP1001643-32.2017.5.02.0605 (SÃO PAULO, 2018) condenou os réus ao cumprimento de inúmeras obrigações de fazer, além do pagamento de reparações civis coletivas, que foram destinadas a entidades filantrópicas e também a programas de esclarecimento acerca dos direitos dos trabalhadores estrangeiros, inclusive prevenção do tráfico de pessoas para fins de trabalho no Brasil e trabalho urbano em situação análoga à escravidão.

\title{
CONSIDERAÇões FINAIS
}

A migração é um antigo fenômeno que a humanidade, desde seus primórdios, exerce, entre vários motivos, destacando-se a manutenção da própria sobrevivência. Nesse cenário, recentemente, tem ganhado espaço a análise de tal fenômeno sob o viés de gênero. A partir de uma leitura interseccional da migração, percebe-se que a antiga compreensão do 
deslocamento temporário ou definitivo da mulher não pode mais ser compreendido apenas em um papel secundário, onde ela acompanha seu pai, marido, entre outros do gênero masculino, sendo estes os verdadeiros protagonistas do processo migratório. Tal compreensão, além de injusta e anacrônica, esconde o protagonismo feminino no fluxo migratório do Brasil e do mundo, velando-se o papel fundamental ocupado pela mulher.

Dessa forma, não são raras as hipóteses em que a mulher, seja por decisão própria ou por circunstâncias que a obrigam, desloca-se em busca de melhores oportunidades de vida ou até mesmo da manutenção da própria sobrevivência e/ou de seus dependentes. Assim, tendo em vista o labor no local destino, o gênero e a formação da mulher migrante serão decisivos para determinar os postos de trabalho ocupados e as atividades a serem desenvolvidas, tendo em vista a existência de uma divisão internacional do trabalho, oriunda do patriarcado, que impõe atividades a serem executadas exclusivamente por mulheres e que, na grande maioria, são consideradas externas às atividades de relevância econômica ou, quando assim são concebidas, estão em patamar inferior às atividades masculinas. Portanto, em grande número, as mulheres migrantes com baixa ou nenhuma formação, acabam ocupando, nos locais de destino, postos de trabalho doméstico, sendo este uma das atividades consideradas externa à relevância econômica.

Tal constatação reforça a divisão internacional sexual do trabalho, quando se reafirma o trabalho doméstico ocupado por mulheres. Nessa situação, a mulher autóctone, a fim de se ver livre a dedicar-se ao mercado de trabalho, terceiriza à mulher migrante o trabalho doméstico. A mulher migrante, visto sua vulnerabilidade no local de destino, aceita tal trabalho, mesmo em condições degradantes.

No Brasil, em que pese a evolução da legislação em relação ao trabalho doméstico, a empregada que labora nessa circunstância ainda não possui direitos equiparados aos demais empregados urbanos e rurais. É nítido os resquícios que tal atividade carrega do período da escravidão, sendo o trabalho doméstico ainda considerado como inferior, sujo e degradante.

Também em outras regiões do mundo, a terceirização do trabalho doméstico à mulher migrante revela o anseio da mulher autóctone em se "libertar" de tal obrigação, relegando à vindoura seu fardo imposto pela divisão sexual do trabalho. Portanto, também nesse contexto o trabalho doméstico é considerado como inferior e destinado àquelas mulheres em situação de vulnerabilidade.

Diante do exposto, decerto que a emancipação das mulheres em relação a uma divisão internacional do trabalho que as relega a trabalhos considerados inferiores só será possível na medida em que os países passam a implantar medidas de fomento à igualdade de gênero, tanto em âmbito interno, quanto por meio de tratados internacionais. A migração feminina, em um mundo globalizado, é um dos fatores que evidenciam essa necessidade imediata, visando extirpar a segregação e o trabalho em condições desumanas.

\section{REFERÊNCIAS}

ALMEIDA, Regis Rodrigues de. Migrações internas. Brasil Escola. Disponível em: https://brasilescola.uol.com.br/geografia/migracoes-internas.htm. Acesso em: 21 dez. 2018. 
BARros, Alice Monteiro de. Curso de Direito do Trabalho, 8. ed. São Paulo: LTr, 2012.

BRASIL. Constituição (1988). Constituição da República Federativa do Brasil. Brasília: Senado Federal, Centro Gráfico, 1988.

. Decreto no 16.107, de 30 de julho de 1923. Aprova o regulamento de locação dos serviços domésticos. Disponível em: http://www2.camara.leg.br/legin/fed/decret/1920-1929/decreto-16107-30-julho-1923-526605-publicacaooriginal-1-pe.html. Acesso em: 20 dez. 2018.

. Decreto n. 95.247, de 17 de novembro de 1987. Regulamenta a Lei nº 7.418, de 16 de dezembro de 1985, que institui o Vale-Transporte, com a alteração da Lei $n^{\circ}$. 7.619, de 30 de setembro de 1987. Disponível em: http:/www2.camara.leg.br/legin/fed/ decret/1980-1987/decreto-95247-17-novembro-1987-445652-publicacaooriginal-1-pe. html. Acesso em: 20 dez. 2018.

Decreto-Lei no $\mathbf{3 . 0 7 8}$, de 27 de fevereiro de 1941. Dispõe sobre a lotação dos empregados em serviço doméstico. Disponível em: http://www2.camara.leg.br/legin/fed/ declei/1940-1949/decreto-lei-3078-27-fevereiro-1941-413020-publicacaooriginal-1-pe. html. Acesso em: 20 dez. 2018.

. Decreto-Lei $\mathbf{n}^{\mathbf{0}} \mathbf{. 5 . 4 5 2}$, de $1^{\circ}$. de maio de 1943. Aprova a Consolidação das Leis do Trabalho. Disponível em: http://www.planalto.gov.br/ccivil_03/decreto-lei/Del5452. htm. Acesso em: 7 set. 2018.

. Decreto Legislativo $\mathbf{n}^{\mathbf{0}}$. 172, de 4 de dezembro de 2017. Aprova os textos da Convenção sobre o Trabalho Decente para as Trabalhadoras e os Trabalhadores Domésticos ( $n^{\circ}$. 189) e da Recomendação sobre o Trabalho Doméstico Decente para as Trabalhadoras e os Trabalhadores Domésticos ( $n^{\circ}$. 201), da Organização Internacional do Trabalho. Disponível em: http://www2.camara.leg.br/legin/fed/decleg/2017/decretolegislativo-172-4-dezembro-2017-785852-publicacaooriginal-154384-pl.html. Acesso em: 16 fev. 2019.

. Emenda Constitucional $\mathbf{n}^{\mathbf{0}}$. 72, de 2 de abril de 2013. Altera a redação do parágrafo único do art. $7^{\circ}$. da Constituição Federal para estabelecer a igualdade de direitos trabalhistas entre os trabalhadores domésticos e os demais trabalhadores urbanos e rurais. Disponível em: http://www.planalto.gov.br/ccivil_03/Constituicao/Emendas/Emc/emc72. htm. Acesso em: 20 dez. 2018.

. Lei no ${ }^{0}$ 3.071, de $1^{\circ}$. de janeiro de 1916. Código Civil dos Estados Unidos do Brasil. Disponível em: http://www.planalto.gov.br/ccivil_03/leis/L3071.htm. Acesso em: 20 dez. 2018.

. Lei no $\mathbf{n}^{\mathbf{5}} \mathbf{5 5 9}$, de 11 de dezembro de 1972. Dispõe sobre a profissão do empregado doméstico e dá outras providências. Disponível em: http://www.planalto.gov.br/ccivil_03 / LEIS/L5859.htm. Acesso em: 20 dez. 2018. 
. Lei $\mathbf{n}^{\mathbf{0}} \mathbf{. 1 0 . 2 0 8}$, de 23 de março de 2001. Acresce dispositivos à Lei no 5.859 , de 11 de dezembro de 1972, que dispõe sobre a profissão de empregado doméstico, para facultar o acesso ao Fundo de Garantia do Tempo de Serviço - FGTS e ao seguro-desemprego. Disponível em: http://www.planalto.gov.br/ccivil_03/Leis/LEIS_2001/L10208.htm. Acesso em: 20 dez. 2018.

. Lei $\mathbf{n}^{\mathbf{0}}$. 11.324, de 19 de julho de 2006. Altera dispositivos das Leis $\mathrm{n}^{\text {os }} 9.250$, de 26 de dezembro de 1995, 8.212, de 24 de julho de 1991, 8.213, de 24 de julho de 1991, e 5.859, de 11 de dezembro de 1972; e revoga dispositivo da Lei $\mathrm{n}^{\circ} 605$, de 5 de janeiro de 1949. Disponível em: http://www.planalto.gov.br/ccivil_03/_Ato2004-2006/2006/Lei/ L113 24.htm. Acesso em: 20 dez. 2018.

. Lei Complementar $\mathbf{n}^{0} . \mathbf{1 5 0}$, de $1^{\circ}$. de junho de 2015. Dispõe sobre o contrato de trabalho doméstico; altera as Leis $\mathrm{n}^{\circ} 8.212$, de 24 de julho de 1991, $\mathrm{n}^{\circ} 8.213$, de 24 de julho de 1991, e no 11.196, de 21 de novembro de 2005; revoga o inciso I do art. $3^{\circ}$ da Lei $\mathrm{n}^{\circ} 8.009$, de 29 de março de 1990, o art. 36 da Lei no 8.213, de 24 de julho de 1991, a Lei $\mathrm{n}^{\circ} 5.859$, de 11 de dezembro de 1972, e o inciso VII do art. 12 da Lei $\mathrm{n}^{\circ} 9.250$, de 26 de dezembro 1995; e dá outras providências. Disponível em: http://www.planalto.gov.br/ ccivil_03/leis/LCP/Lcp 150.htm. Acesso em: 20 dez. 2018.

CASTRO, Nancy Toledo de; AGUIAR, Lais Silva; MUNHOZ, Andréa Rodrigues. Os trabalhadores domésticos e os direitos sociais no Direito do Trabalho. Revista das Faculdades Integradas Vianna Júnior, Juiz de Fora, v. 5, n. 1, jan./jun. 2015. Disponível em: http://www.viannasapiens.com.br/revista/article/view/151/137. Acesso em: 16 fev. 2019.

COSTA, Joaze Bernardino. Migração, trabalho doméstico e afeto, 2012. Disponível em: http://www.scielo.br/scielo.php?script=sci_arttext\&pid=S0104-83332012000200016. Acesso em: 16 fev. 2019.

COTRIM, Gilberto. História global: Brasil e geral, 6. ed. São Paulo: Saraiva, 2002.

DANTAS, Manuela Corradi Carneiro. A situação do imigrante no Brasil sob a perspectiva do Direito do Trabalho, 2017, 122s. Dissertação (Mestrado) - Programa de Pós-Graduação em Direito, Pontifícia Universidade Católica de Minas Gerais, Belo Horizonte, 2017. Disponível em: http://www.sistemas.pucminas.br/BDP/SilverStream/Pages/ pg_ConsItem. html. Acesso em: 7 set. 2018.

DUTRA, Delia. Mulheres, migrantes, trabalhadoras: a segregação no mercado de traba1ho. Revista Interdisciplinar de Mobilidade Humana, Brasília, Ano XXI, n. 40, jan./jun. 2013, p. 177-193.

. Mulheres migrantes peruanas em Brasília: $\mathrm{O}$ trabalho doméstico e a produção do espaço na cidade, 2012, 250s. Tese (Doutorado) - Programa de Pós-Graduação em So- 
ciologia, Universidade de Brasília, Brasília, 2012. Disponível em: http://repositorio.unb.br/ bitstream/10482/11418/1/2012_DeliaMariaDutraSilveiraMargalef.pdf . Acesso em: 7 set. 2018.

FRANCISCO, Wagner de Cerqueira e. Migração interna no Brasil. Brasil Escola. Disponível em: https://brasilescola.uol.com.br/brasil/migracao-interna-no-brasil.htm. Acesso em: 7 set. 2018.

ILLES, Paulo, et al. Mulheres migrantes e refugiadas trabalhadoras domésticas na cidade de São Paulo e região metropolitana, 2018. Disponível em: https://ptnacamara.org.br/portal/wp-content/uploads/2018/02/mulheres_migrantes-4-1.pdf. Acesso em: 16 fev. 2019.

INSTITUTO BRASILEIRO DE GEOGRAFIA E ESTATÍSTICA. Trabalho doméstico reduz desocupação, mas reforça informalidade. Disponível em: https://agenciadenoticias.ibge.gov.br/agencia-noticias/2012-agencia-de-noticias/ noticias/18435-trabalho-domestico-reduz-desocupacao-mas-reforca-informalidade. Acesso em: 16 fev. 2019.

LE GUILLANT, Louis. Incidências psicopatológicas da condição de empregada doméstica. In: LIMA, Maria Elizabeth Antunes (Org.). Escritos de Louis Le Guillant: da ergoterapia à psicopatologia do trabalho. Rio de Janeiro: Vozes, 2006, p. 242-286.

LISBOA, Tereza Kleba. Fluxos migratórios de mulheres para o trabalho reprodutivo: a globalização da assistência. Revista de Estudos Feministas, n. 3, v. 15, p. 805-821, Florianópolis, set./dez. 2007.

MACHADO, Maria Helena Pereira Toledo. Mulher, corpo e maternidade. In: SCHWARCZ, Lilia Moritz; GOMES, Flávio. (orgs.). Dicionário da Escravidão e Liberdade, 1. ed. São Paulo: Companhia das Letras, 2018, p. 334-342.

MICHAELIS. Michaelis: moderno dicionário da língua portuguesa. Dicionários Michaelis. São Paulo: Companhia Melhoramentos, 2016, 992 p.

ORGANIZAÇÃO DAS NAÇÕES UNIDAS. Estudios de población, nº. 47. In: Métodos de medición de la migración interna. Manual VI. Nova York: Naciones Unidas, 1972. Disponível em: https://www.worldcat.org/title/metodos-de-medicion-de-la-migracion-interna/oclc/892175931?referer=di\&ht=edition. Acesso em: 21 dez. 2018.

Força de trabalho global conta com 150 milhões de migrantes, diz estudo da OIT. Disponível em: <https://nacoesunidas.org/forca-de-trabalho-global-conta-com-150-milhoes-de-migrantes-diz-estudo-da-oit/>. Acesso em: 16 fev. 2019. 
. ILO global estimates on migrant workers. Disponível em: $<$ http://ilo.org/global/topics/labour-migration/publications/WCMS_436343/lang--en/index.htm>. Acesso em: 16 fev. 2019.

. ONU MULHERES. Trabalho de cuidados oscila entre 10 e $39 \%$ do PIB de países, considera ONU MULHERES. Disponível em: <http://www.onumulheres.org.br/ noticias/trabalho-de-cuidados-oscila-entre-10-e-39-do-pib-de-paises/>. Acesso em: 16 fev. 2019.

. Trabalho doméstico não remunerado representa até $39 \%$ do PIB de países, diz ONU MULHERES. Disponível em: < https://nacoesunidas.org/trabalho-domestico-nao-remunerado-representa-ate-39-do-pib-dos-paises-diz-onu-mulheres/>. Acesso em: 16 fev. 2019.

ORGANIZAÇÃO INTERNACIONAL DO TRABALHO. Brasil ratifica Convenção 189 da OIT sobre trabalho doméstico. Disponível em: https://www.ilo.org/brasilia/noticias/ WCMS_616754/lang--pt/index.htm. Acesso em: 16 fev. 2019.

. Estimativas Globais da OIT sobre Trabalhadores Migrantes, 2017. Disponível em: https:/www.ilo.org/wcmsp5/groups/public/\%E2\%80\%94 dgreports/\%E2\%80\%94dcomm/\%E2\%80\%94publ/documents/publication/wcms_652029.pdf. Acesso em: 16 fev. 2019.

. Ratifications of C189: Domestic Workers Convention, 2011 (No. 189). Disponível em: <ttps:/www.ilo.org/dyn/normlex/en/f?p=NORMLEXPUB: 11300:0::NO:11300:P11300_INSTRUMENT_ID:2551460:NO>. Acesso em: 16 fev. 2019.

. Trabalho Doméstico. Disponível em: $<$ https://www.ilo.org/brasilia/ temas/trabalho-domestico/lang--pt/index.htm>. Acesso em: 16 fev. 2019.

. Social protection for domestic workers: Key policy trends and statistics, 2016. Disponível em: https://www.ilo.org/wcmsp5/groups/public/---ed_protect/---soc_sec/documents/publication/wcms_458933.pd. Acesso em: 16 fev. 2019.

ORGANIZAÇÃO INTERNACIONAL PARA AS MIGRAÇÕES. Conceitos básicos de migração, 2014. Disponível em: http://www.csem.org.br/pdfs/conceitos_basicos_de_migracao_segundo_a_oim.pdf. Acesso em: 07 set. 2018.

PARELLA RUBIO, Sònia. Segregación laboral y "vulnerabilidad social” de la mujer inmigrante a partir de la interacción entre clase social, género y etnia. In: FLAQUER, Lluís; SOLÉ, Carlota (Orgs.). El uso de las políticas sociales por las mujeres inmigrantes. Madrid: Instituto de la Mujer. Ministerio de Trabajo y Asuntos Sociales, 2005, p. 97-136. 
SÃO PAUlO. Código de Posturas do Município de São Paulo/1886. Disponível em: https://archive.org/details/CodigoDePosturasDoMunicipioDeSaoPaulo1886/page/n1. Acesso em: 20 dez. 2018.

. Tribunal Regional do Trabalho. Processo: ACP 1001643-32.2017.5.02.0605.

Relator: Jaime Ramos. Florianópolis, 10 jan., 2008. Disponível em: http://tj-sc.jusbrasil. com.br/jurisprudencia/6313445/apelacao-civel-ac-275145-sc-2005027514-5/inteiro-teor-12436269. Acesso em: 19 jul. 2014.

SERTÓRIO, Lidiane Bruno; SANTOS, Miriam de Oliveira. Relações entre trabalho, educação, gênero e migração. Disponível em: http://www.estudosdotrabalho.org /anais-vii-7-seminario-trabalho-ret-2010/Lidiane_Bruno_Sertorio_e_Miriam_de_Olivei ra_Santos_relacoes_entre_trabalho_educacao_genero_e_migracao.pdf. Acesso em: 21 dez. 2018.

SOUZA, Carlos Santana de. Gênero, linguagens e etnicidades. Símbolos e Alegorias do preconceito: Uma leitura do conto "Maria Caboré, de Ronaldo Correia de Brito (Org.). BORGES, L. et al. Goiânia-GO: FUNAPE, 2013.

\section{DAdos doS AUTORES}

\section{Gustavo Marcel Filgueiras Lacerda}

Mestrando em Direito Privado pela Pontifícia Universidade Católica de Minas Gerais. Bolsista da CAPES. É licenciado em Filosofia pelo Instituto Santo Tomás de Aquino e bacharel em Direito pela Escola Superior Dom Helder Câmara. Advogado.gusfilgueiras@gmail.com

\section{Camila de Paula Guimarães Baía}

Bacharel em Direito pela Pontifícia Universidade Católica de Minas Gerais. Pós-graduada em Direito de Empresa pelo Instituto de Educação Continuada (IEC) da Pontifícia Universidade Católica de Minas Gerais. Advogada. camilabaianotebook@gmail.com

Submetido em: 27-3-2019

Aceito em: 16-9-2020 